\title{
A pilot study to assess manufacturing processes using selected point measures of vibroacoustic signals generated on a multitasking machine
}

\author{
Mariusz Deja ${ }^{1}$ (D) $\cdot$ Roksana Licow ${ }^{2}$ (D) \\ Received: 10 August 2020 / Accepted: 24 September 2020 / Published online: 6 October 2020 \\ (C) The Author(s) 2020
}

\begin{abstract}
The article presents the method for the evaluation of selected manufacturing processes using the analysis of vibration and sound signals. This method is based on the use of sensors installed outside the machining zone, allowing to be used quickly and reliably in real production conditions. The article contains a developed measurement methodology based on the specific location of microphones and vibration transducers mounted on the tested object, in this case on a four-axis CNC ST20Y Haas lathe. A mobile phone was integrated into the measuring system and used to control the measurement process. The results from the analysis of vibration and sound signals recorded during different machining operations are presented. They refer to selected working conditions of a machine tool depending on switching the coolant supply on or off and different machine loads caused by various technological processing as well as the various speed of the positioning movements. The analysis was carried out using selected point measures describing the vibroacoustic signals. The synthesis conducted on the basis of results from the experiments indicates the validity of using vibration and acoustic signals, recorded outside the machining area, to evaluate material removal processes that are diverse in terms of kinematics and processing conditions. It indicates the possibility of using proposed point measures of vibroacoustic signals in the diagnostic aspects of the machine tools to achieve high dimension and shape accuracy and to evaluate the condition of the technological devices in terms of their optimal efficiency. Presented methodology can be used as a supporting tool in the $\mathrm{CAD} / \mathrm{CAM}$ software for a better selection of appropriate cutting parameters and for a wireless control of manufacturing systems consisting of several machine tools.
\end{abstract}

Keywords Vibroacoustic signals $\cdot$ Wireless control $\cdot$ Manufacturing systems $\cdot$ CNC machining $\cdot$ Condition monitoring

\section{Introduction}

The monitoring of machining can increase the efficiency of production processes aside from ensuring the required quality of manufactured parts. In addition, production activities have

Mariusz Deja

mariusz.deja@pg.edu.pl

Roksana Licow

roksana.licow@pg.edu.pl

1 Department of Manufacturing and Production Engineering, Faculty of Mechanical Engineering, Gdańsk University of Technology, Gdańsk, Poland

2 Department of Rail Transportation and Bridges, Faculty of Civil and Environmental Engineering, Gdańsk University of Technology, Gdańsk, Poland to undergo global changes to considerably reduce greenhouse gas emissions as suggested by Rao in [1]. Different types of sensors can be used for reliable tool condition monitoring (TCM) along with predicting the surface quality and the energy consumption leading to energy-efficient machining. Accurate and quick diagnostics of cutting processes ongoing in the machining zone can help in selecting proper technological parameters. Modern machine tools known as multitasking machines (MTM) are equipped with multiple spindles and turrets allowing simultaneous performance of various operations, mostly milling and turning but also others, for instance grinding or laser hardening [2-4]. This allows producing a wide spectrum of parts, e.g., with complex swept surfaces or sculptured elements from different industrial sectors for automobile, aerospace, and medical applications. Multitasking machines can reduce the number of necessary machining steps required for the complete machining of a whole part in one setup, without the inter-machine part transfers as is the case 
when single machine tools are used for milling and turning operations $[5,6]$. The appropriate usage of technologically advanced MTM equipped with apparatuses of high capabilities is an important topic for ensuring an increased production efficiency [7]. This can be realized by the full integration of computer systems supporting activities related to manufacturing issues, including computer-aided design (CAD), computer-aided process manufacturing (CAM), and computer-aided process planning (CAPP) [8-11]. Even high-fidelity simulations may differ from a process that is carried out on a machine tool, without consideration of a feedback from relevant monitoring systems. To achieve the convergence between physical and virtual spaces, a cybernetic representation of all manufacturing elements has been developed as a concept/method of digital twin [12]. Taking into account the response from the physical world, a living model in the cyber world has to be continuously updated and changed as the physical counterpart is changing. The operational dynamics is crucial for the twin's behavior which is based on near real-time data coming from the physical counterpart [12]. Monitoring, control, diagnostics, and prediction using networking and sensors are possible applications of a digital twin in manufacturing environment. In particular, sensor fusion based on the combined measurements of different signals may provide a more thorough information about the analyzed process and allow for precise process monitoring and diagnostics.

The authors developed a method based on the analysis of vibration and acoustic signals for the evaluation of selected technological processes carried out on mill-turn centers. Design of mill-turn parts affects the course of the cutting process characterized by the variable machining conditions and changeable physical phenomena. Taking into account the industrial implementation limitations, e.g., the accessibility of machining zone, complexity of measurements, and typically large number of machine tools located in the workshop space, proposed method is based on the use of sensors outside the machining zone, allowing to be used quickly in real production conditions. The analysis was carried out using selected point measures estimated from the vibroacoustic signals. The results from the experiments indicated the validity of using vibration and acoustic signals recorded outside the machining area to evaluate selected machining processes characterized by the variable machining conditions and changeable physical phenomena. Different locations of sensors have been checked and the most suitable location, giving the most reliable data with the similar tendencies for the sound and vibration signals, was designated.

The results indicated the possibility of using proposed point measures of vibroacoustic signals in the monitoring and diagnostic aspect of the machine tools. This could help to achieve a higher dimension and shape accuracy and to avoid defective products. Due to different requirements and some technological limitations, the implementation of digital twins in real industrial practice should be individually suited and the proper reference models for the digital twin in design and production engineering should be built as suggested in [13]. Proposed method is relatively simple and suitable for collecting reliable data from the physical environment consisting of advanced technological machine tools. The obtained data could be used to build a reference model for the "shaped digital twin" in manufacturing parts with a combination of milling and turning features or as a supporting tool for $\mathrm{CAD} / \mathrm{CAM} / \mathrm{CAPP}$ software as well as for a simple and wireless control of manufacturing systems consisting of several machine tools.

Section 2 of the paper contains a review of research performed in the area of process monitoring, particularly with regard to vibration and sound signals generated during machining and used for diagnostics of cutting processes and detection of potential failures during material removal. The main objectives of the paper, arising from some ideas and shortcomings of other authors, are also presented. In Section 3, the research object and the procedure for measuring vibroacoustic signals on a mill-turn center are described. Section 4 gives the details of the developed research methodology based on the selected point measures to assess processes for making a millturn part. Section 5 presents the results from the experiments and the analysis of vibroacoustic signals, including determined point measures and time-frequency analysis. Finally, the authors' contributions are summarized and further research directions are formulated in Section 6.

\section{Review of related research work}

In industrial practice, sensors which are used for process monitoring should be cheap and reliable in obtaining information signals related to machining operations. Vibrations, temperature, cutting forces, motor-related parameters, acoustic emission, and sound signals generated during machining are closely linked with tool state and process conditions, allowing the diagnostics of cutting processes and detection of potential failures during material removal [14-17]. In addition, condition monitoring systems must not interfere with the machining process and should be based on a simple communication as well as quick analysis of collected data. The proper setup and placing of a monitoring sensor are the crucial factors affecting the proper correlation between obtained signals and various machining characteristics $[15,18]$.

Motor-related parameters such as motor power or current meet abovementioned requirements and are commonly used for monitoring material removal processes to detect malfunctions in the cutting operations [15]. They can also detect the defects in the workpiece material as shown by Licow et al. on the example of wood sawing [19]. The 
increase in the average electric power of the main drive allowed for the identification of knots during the wood sawing process. The cost aspects have been strongly emphasized by Zhang and Chen [20] who demonstrated an effective tool condition monitoring approach in end milling, based on the vibration signal collected through a cheap microcontrollerbased data acquisition system.

The cutting parameters themselves influence a part quality but also the vibration behavior during processing which, in turn, strongly affects the shape accuracy and the surface roughness, as reported by $\mathrm{Wu}$ and Lei [21] on the example of milling experiments. Thus, apart from the monitoring, the determination of optimal process parameters can be an effective way of the vibration reduction during machining allowing the increase of a part quality. Kaliński and Galewski [22] suggested an original procedure of the spindle speed optimisation, based on the Liao-Young criterion, in order to reduce vibration level during ball end milling of flexible parts. Another approach to avoid the vibration during machining by adjusting the stiffness of the workpiece holder to the real cutting conditions was presented by Kaliński et al. in [23]. The calculation of the optimum stiffness has to be performed before milling, based on the workpiece's modal identification results and the finite element model simulations. The proposed approach is promising but difficult to implement in industrial conditions where a wide range of machine components would require advanced analysis. Sun et al. also paid attention to the fixturing by analyzing the excitation induced by the cutting forces and the dynamic interaction between the workpiece and the fixture [24]. The proposed approach was based on the real-time dynamic clamping force monitoring and could be effectively used in milling, e.g., for thin-walled structures such as impellers or blisks. Mou et al. [25] pointed out that apart from fixture type, the spindle rotation in air-cut may exert a significant influence on the vibration signal related to the mechanical characteristics of the spindle system.

Due to the practical difficulties with the application of some TCM systems, an integrated wireless vibration sensing tool holder has been developed by Xie et al. for tool condition monitoring during milling without interfering with the cutting process [26]. Liu et al. proposed an indirect method to measure the vibration of the tool tip from the vibration of the measurement point selected on a turret. It allowed for an easy and safe installation of an accelerometer located far away from the cutting and chip evacuation zones [27]. Obtained results indicated high effectiveness of the proposed indirect measurement method applicable also in other processes as shown in [28] for spindle vibration-based tool wear monitoring in micromilling. Jáuregui et al. [29] used vibration and cutting force signals for estimating the tool condition in the highspeed micromilling process. They pointed out that the combination of two signals provided more reliable estimations with the improved sensing bandwidth. Lu and Wan [30] studied high-frequency sound signals for tool wear monitoring in micromilling. Their results indicated that the normalized sound signals obtained from a single microphone with a frequency range between 20 and $80 \mathrm{kHz}$, which is above the upper limit of frequency range for human hearing, demonstrated the high potential to distinguish a worn tool from a sharp one.

Very wide sensor dynamic bandwidth from 100 to $900 \mathrm{kHz}$ is characteristic for acoustic emission (AE) measured by piezoelectric sensor technology which can detect most of the phenomena in machining, such as chip formation and morphology, surface quality, and tool wear progression for different machining operations and materials [15, 18]. Kishawy et al. [18] concluded on the basis of studies which employed $\mathrm{AE}$ in monitoring that the frequency domain spectrum analysis is better than the time domain for finding an adequate correlation between AE signals and various machining characteristics.

Sound sensors, which are basically microphones, have recently attracted the research attention, although the use of the sound measurement technique in an industrial environment is not much popular due to the restrictions imposed by the presence of other disturbing noises [31]. On the other hand, it is well known form the industry that an experienced operator of a machine tool is able to recognize e.g. a dull tool due to sound which is generated during the machining process, even at a considerable distance from the machining area. In practice, the sound signal is typically received with a low signal-to-noise ratio and the feature sound may be hidden as pointed out by Zhong et al. [32]. They suggested the blind source separation method for recovering the feature sound signals from observed signals. Easy mounting on the machine tool with good ratio cost/benefit was indicated by Salgado and Alonso [33] as the main advantages of sound sensors. The cost of their application is much lower comparing to techniques based on other sensors, although it was pointed out in [33] that the sound signal should be used as an additional signal in the tool condition monitoring system (TCMS) which was developed for turning processes using sensor fusion and artificial neural networks. The accuracy of the proposed TCMS for online tool wear monitoring based on the feed motor current and the sound signal emitted during turning increased with the increase in cutting speeds and feed rates. Not the sound signal but the vibration in the feed direction and the motor current signals were the features that were most correlated with the tool wear and best suited for the development of a reliable TCMS in analyzed turning processes [33]. Nevertheless, audible sound sensors were successfully applied in many other TCMS for monitoring of milling and turning as well as for other manufacturing processes as shown in next paragraphs of this chapter.

Rubio and Teti [14] characterized and classified the audible sound energy signals and proposed the systematic 
methodology to set up comparable tests for the analysis of the sound signal generated during different milling operations carried out on a milling machine tool. Ai et al. [34] showed that the tool wear during milling can be monitored using the cutting sound acoustic spectrum. Kothuru at al. [35] used audible sound signals in the Support Vector Machine (SVM) learning model to detect the cutting tool wear and failure during end milling operation. The influence of the hardness variation on the sound signal related to the cutting tool wear in end milling was studied by Kothuru et al. in [36]. Shankar et al. [37] designed an efficient TCMS using the resultant machining force and sound acquired while the milling process. Higher amplitude of cutting force and sound generated during machining with a dull tool confirmed a strong correlation of the flank wear with sound pressure and cutting force signals. The tool condition was estimated with the Artificial Intelligence (AI) techniques based on the acquired signals. The decision tree and discrete wavelet transform (DWT) techniques with sound signals were proposed by Madhusudana et al. [38, 39] for fault diagnosis of the face milling tool. Close correlation between the acoustic signal and the cutting forces, material removal rate, and tool deflection as well as surface error was reported in [40] for free form milling with the use of a ball end milling cutter. This type of machining is usually characterized by the variations in feed rate. The results presented in [41] showed that the method based on synchrosqueezing transform of sound signals has a great potential to be used for the online chatter detection in the highspeed milling process.

$\mathrm{Lu}$ and Kannatey-Asibu pointed out in [42] that sound signals were generated by the interaction between the asperities on the surfaces of the cutting tool and workpiece in turning. Additionally to the audible sound signals, other signals such as force, vibration, and acoustic emission were measured. The accelerometers were installed on the tool holder very close to the tool insert in the feed and cutting directions. The microphone was mounted at a distance of $17.8 \mathrm{~mm}$ away from the cutting zone. Seemuang et al. used microphone to measure the audible sound emitted during face turning in a wet cutting condition using constant surface speed control [43]. Although there was no relationship between the frequency of spindle noise and tool wear (the frequency was constant), the magnitude of spindle noise frequency increased with the progression of the tool wear. Online monitoring based on the maximum peak-to-peak amplitude of the sound signal was successfully applied to predict the surface quality of the machined surface in intermittent turning of magnesium workpieces [44].

Apart from turning and milling, also other processes have been effectively monitored using the audible as well as high-frequency sound signals. Yusof et al. [45] demonstrated the feasibility of using arc sound signal acquired during the welding process of gas pipeline steel to detect subsurface defects, i.e., porosity, with the aid of a signal processing method. Ubhayaratne et al. [46] pointed out the simplicity of low-cost audio signal analysis during monitoring of stamping process and confirmed a significant qualitative correlation between emitted sound signals and the wear state of sheet metal stamping tools. Monitoring of grinding processes was proposed in [47] and in [48]. Licow et al. [19] investigated the impact of the pine wood impregnation process on the generated noise level when cutting wood on the sash gang saw. Obtained results indicated that monitoring based on the analysis of sound signals can be used as a supplementary source of information related to the wood cutting processes. The effect of wood impregnation was statistically significant for the sound level at a lower value of the feed speed, and for the cutting power at the higher feed rate.

Summing up, many researchers have focused on the vibration and sound signal analysis. The latter one is a possible and relatively simple and cheap method to monitor the tool wear and to predict quantities characterizing machined surface. The basic objective of this paper was to find the relationship between the sound and vibration signals, associated with processing turning and milling features on a four-axis CNC ST20Y Haas lathe. To the best knowledge of the authors, there is no systemic study on the analysis of vibroacoustic signals generated on a multitasking machine tool and at the same time dedicated to milling and turning processes which vary in terms of kinematics and processing conditions. The experiments have been conducted according to some indications of other authors. Sensor fusion based on the combined measurements of an audible sound signal and the vibrations allowed for a more thorough information about the analyzed process and indicated the possible applications of the proposed online monitoring of machining processes. Although traditional wired sensors were used, all signals were easily collected and not intrusive in the performed processes as the measuring points were located outside the cutting and chip evacuation zones. The signals were collected during wet and dry cutting and also during "air-cut" with the variations in the speed of positioning movements. The measuring apparatus was effective and cost-competitive for monitoring machining processes as it can be easily installed on any machine tool in the shop floor. The simple and wireless control of the measurement process was implemented by the integration of the mobile phone into the measuring system. For all tests, the changes in the values of selected point measures of vibration and sound signals were estimated and mutually compared to show the effectiveness of different signals collected with the constant noise level, without the influence of other devices and under the same ambient conditions. 


\section{Research object}

In the tests carried out, point measures of vibroacoustic (VA) signals generated during machining on a four-axis CNC ST20Y Haas lathe (Fig. 1) were determined. This machine tool can be used for producing both milling and turning machining features. Vibroacoustic signals were measured in three points related to characteristic elements of an analyzed machine tool, marked as A, B, and C in Fig. 1. The acoustic signals were recorded by two 4189-A-021 Brüel \& Kjær microphones, in the further analysis referred to as MIC A and MIC B, while the vibration signals were measured by 4504-A and 4513 Brüel \& Kjær transducers. Miniature Triaxial CCLD Accelerometer Type 4504-A is a triaxial piezoelectric accelerometer with three independent outputs for simultaneous high-level measurements in three mutually perpendicular directions within the ranges from 1 to $9000 \mathrm{~Hz}$ in $\mathrm{X}$ and $\mathrm{Y}$ directions and from 1 to $18,000 \mathrm{~Hz}$ in $\mathrm{Z}$ direction. Each transducing element was individually calibrated. The 4513 transducer was a single-axis piezoelectric accelerometer with a measuring range from 1 to $10,000 \mathrm{~Hz}$. For both microphones, the frequency measuring range was 20 to $20,000 \mathrm{~Hz}$. The vibration sensors were attached to the object with a neodymium $\mathrm{NdFeB}$ magnet.
The single acoustic signal from a microphone MIC A and three vibration signals from a triaxial transducer were measured in the point A located behind the main spindle-Fig. 1. Another microphone MIC B was located at the measuring point $\mathrm{B}, 200 \mathrm{~mm}$ away from the cover of a machine tool at the height of the spindle axis. The single-axis vibration transducer was placed on one of the front load-bearing elements of the machine tool, closer to the machining chuck-the measuring point $\mathrm{C}$.

Vibroacoustic signals were recorded in real time using a 3050-A-060 Brüel \& Kjær multi-purpose input module enabling connection of vibration transducers and microphones by using BNC cables in six available channels. During recording, the low pass filter was set to $1 \mathrm{~Hz}$ for transducers and to $7 \mathrm{~Hz}$ for microphones. The high pass filter was set to $25.6 \mathrm{kHz}$ to perform measurements within the specified ranges of all sensors.

The sampling frequency was $65.536 \mathrm{kHz}$, so the corresponding Nyquist frequency was $32.768 \mathrm{kHz}$. During conducted measurements, significant signal changes occurred at the frequency of up to $2.500 \mathrm{kHz}$, which was accepted as a reliable value for the further analysis because it was much lower than the calculated Nyquist frequency. LAN-XI Notar $^{\mathrm{TM}}$ software allowed the stand-alone recording of
Fig. 1 Schematic drawing of measurements of vibroacoustic signals on a mill-turn center

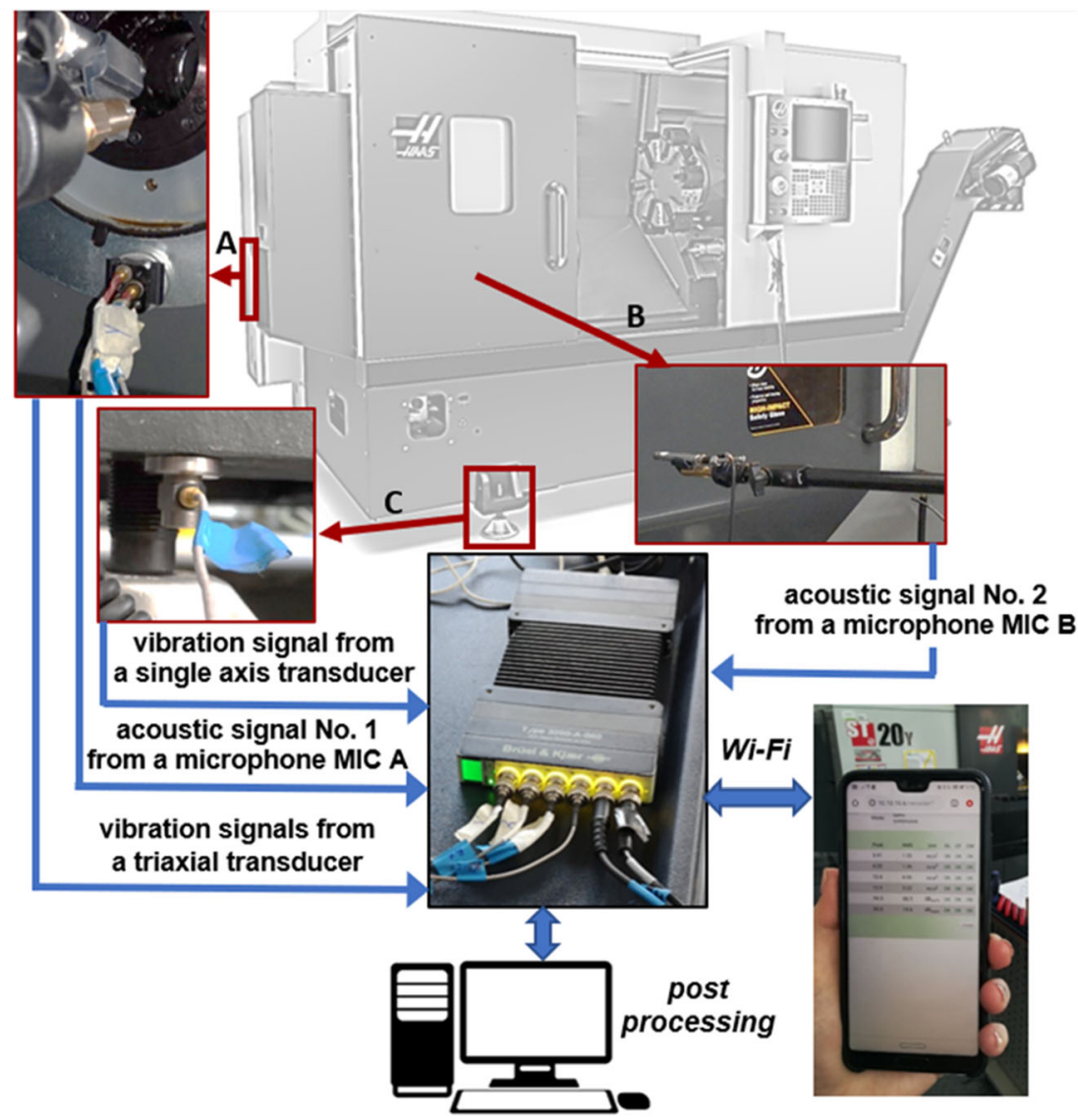


measured signals. Sound and vibration measurements were controlled through a WI-FI connection between a mobile phone and the 6-channel input module-Fig. 1.

\section{Research methodology}

The measured vibroacoustic signals referred to producing a part made of 7075 aluminum alloy-Fig. 2. The tests were intended to eliminate excessive wear of the cutting insert that occurred during the turning operation and resulted in the production of defective products.

The machining features that comprised the analyzed part were produced by the following processes: turning, milling, and cutting off. In order to assess the suitability of the proposed point measures of sound and vibration signals generated on a four-axis CNC ST20Y Haas lathe, four tests were realized in accordance with Table 1. In the first test, the VA signals were generated by the machine tool without processing ("air-cut" with no cooling) but during the movements and rotations of the working components of a machine tool according to the $\mathrm{CNC}$ part program generated for a given part. The cooling supply was switched on during the second test of the idle work. During the third and fourth test, signals were generated at the same time by the elements of a machine tool and by the process of material cutting as well as by cooling. For all tests, the changes in the values of point measures of vibration and sound signals were estimated.

Real-time VA signals were acquired and the analysis of effective vibration values and sound levels was carried out for them-Fig. 3. VA signals changed over time, depending on the settings and processing conditions given in Table 1.

Based on the time domain analysis, time windows of signals belonging to performed processes were cut out-Fig. 4 . Signals from time windows were used for the determination of point measures. In addition, reference signals for each direction of measured vibrations and for both microphones were

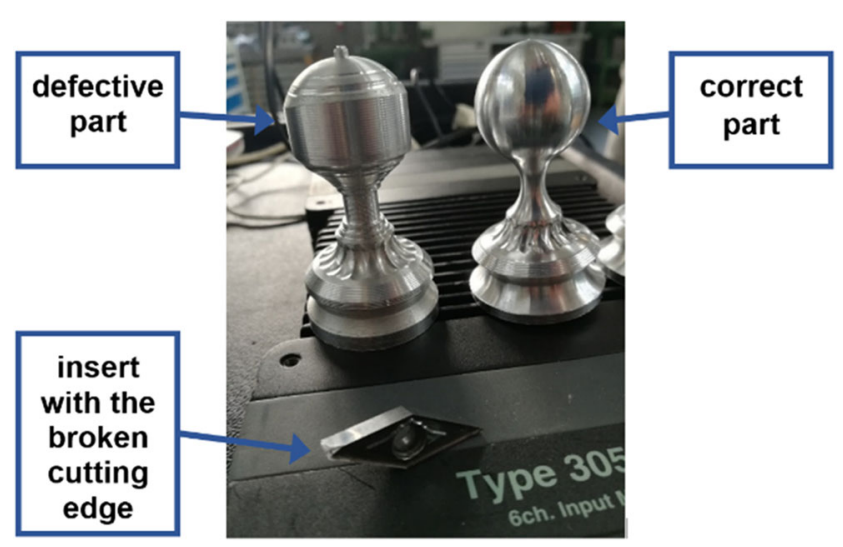

Fig. 2 Sample parts produced on a four-axis CNC ST20Y Haas lathe also selected. The reference signals were used to calculate the dynamics of changes in the diagnostic parameters values.

Point measures are widely used as reliable features in the VA diagnostics to describe the signals of displacement, velocity, or acceleration. Single value and non-dimensional point measures describe changes in the VA signal based on dimensional point measures, which are the result of changes in the technical conditions of the tested object [49].

The crest factor $C_{A}$ and the dynamics of changes of the diagnostic parameter (DCDP) were selected as point measures for the assessment of conducted manufacturing processes. The crest factor is a dimensionless discriminant calculated from the formula:

$C_{A}=\frac{S_{P E A K}}{S_{R M S}}$

where $S_{\text {PEAK }}$ is a peak amplitude and $S_{\mathrm{RMS}}$ is a root mean square amplitude.

The following Eqs. (2) and (3) can be used to calculate the $S_{\text {PEAK }}$ and $S_{\text {RMS }}$ values:

$$
\begin{aligned}
& S_{\text {PEAK }}=\left[\frac{1}{T} \int_{0}^{T}|s(t)|^{\infty} d t\right]^{\frac{1}{\infty}} \\
& S_{R M S}=\sqrt{\frac{1}{T} \int_{0}^{T}[s(t)]^{2}} d t
\end{aligned}
$$

The peak amplitude is used to describe signals that have impulse and shock characteristics. The root mean square amplitude is one of the most commonly used point measures due to its proportionality to the power of the analyzed process.

The dynamics of changes of the diagnostic parameter given in decibels $[\mathrm{dB}]$ is expressed by the equation:

$D C D P=20 \log _{10}\left(\frac{\mu_{u}}{\mu_{R}}\right)$

where

$\mu_{\mathrm{u}}$ a point measure of vibrations during processing (turning, milling, cutting off),

$\mu_{\mathrm{R}} \quad$ a point measure of a reference signal.

$S_{\text {PEAK }}$ and $S_{\text {RMS }}$ amplitudes expressed in Relations (2) and (3), respectively, were selected as point measures during further analysis. Their values were estimated by using the standard procedures available in the PULSE REFLEX 21 B\&K software.

\section{Analysis of vibroacoustic signals from experimental results}

Table 2 presents the values of $S_{\text {RMS }}$ and DCDP point measures estimated for the test no. 1 conducted in compliance with 
Table 1 Parameters of tests during measuring vibroacoustic signals generated on the four-axis CNC ST20Y Haas lathe

\begin{tabular}{|c|c|c|c|c|}
\hline Test no. & Processing & & Workpiece & Rapid tool movements \\
\hline 1 & $\begin{array}{l}\text { Work of a machine tool according to } \\
\text { CNC part program for: } \\
\text { - Turning } \\
\text { - Milling } \\
\text { - Cutting off }\end{array}$ & Coolant off & No workpiece & $\begin{array}{l}25 \% \text { of the feed declared under } \mathrm{G} 00 \\
\text { command, } 100 \% \text { of the working feed } \mathrm{F}\end{array}$ \\
\hline 2 & $\begin{array}{l}\text { Work of a machine tool according to } \\
\text { CNC part program for: } \\
\text { - Turning } \\
\text { - Milling } \\
\text { - Cutting off }\end{array}$ & Coolant on & No workpiece & $\begin{array}{l}25 \% \text { of the feed declared under } \mathrm{G} 00 \\
\text { command, } 100 \% \text { of the working feed } \mathrm{F}\end{array}$ \\
\hline 3 & $\begin{array}{l}\text { Machining according to } \mathrm{CNC} \text { part program for: } \\
\text { - Turning } \\
\text { - Milling } \\
\text { - Cutting off }\end{array}$ & Coolant on & P1 & $\begin{array}{l}25 \% \text { of the feed declared under G00 } \\
\text { command, } 100 \% \text { of the working feed } \mathrm{F}\end{array}$ \\
\hline $\begin{array}{l}4 \\
\text { Cutting } \mathrm{P}\end{array}$ & $\begin{array}{l}\text { Machining according to CNC part program for: } \\
\text { - Turning } \\
\text { - Milling } \\
\text { - Cutting off } \\
\text { rameters for all tests }\end{array}$ & Coolant on & $\mathrm{P} 2$ & $\begin{array}{l}100 \% \text { of the feed declared under G00 } \\
\text { command, } 110 \% \text { of the working feed } \mathrm{F}\end{array}$ \\
\hline \multicolumn{2}{|l|}{ Turning } & Milling & \multicolumn{2}{|l|}{ Cutting off } \\
\hline \multicolumn{2}{|c|}{$\begin{array}{l}\text { Constant cutting speed: } v_{\mathrm{t}}=250 \mathrm{~m} / \mathrm{min} \\
\text { Feed: } f_{\mathrm{t}}=0.2 \mathrm{~mm} / \mathrm{rev}\end{array}$} & $\begin{array}{l}\text { Constant rotational speed: } \\
\quad n_{\mathrm{m}}=2000 \mathrm{rev} / \mathrm{min} \\
\text { Feed: } f_{\mathrm{m}}=100 \mathrm{~mm} / \mathrm{min}\end{array}$ & \multicolumn{2}{|c|}{$\begin{array}{l}\text { Constant cutting speed: } v_{\mathrm{c}}=200 \mathrm{~m} / \mathrm{min} \\
\text { Feed: } f_{\mathrm{c}}=0.15 \mathrm{~mm} / \mathrm{rev} \\
\text { Rotational speed limit: } n_{\max }=2000 \mathrm{rev} / \mathrm{min}\end{array}$} \\
\hline
\end{tabular}

CNC part program generated for required processes (turning, milling, and cutting off) but without machining the workpiece and when the coolant was off. The obtained results are given for specific directions of vibration registrations realized by the triaxial and single-axis transducers. The $\mathrm{X}_{3}, \mathrm{Y}_{3}$ and $\mathrm{Z}_{3}$ measuring directions correspond to $Z^{\prime}, X^{\prime}$, and $Y^{\prime}$ axes of the coordinate system associated with the workpiece coordinated system rotated by $45^{\circ}$ around the spindle axis-Fig. 5. The last two columns in Table 2 present the values of $S_{\mathrm{RMS}}$ and DCDP point measures estimated for sound signals registered by both microphones: MIC A and MIC B. It was assumed that the noise level was constant during all experiments conducted on the same machine tool, without the influence of other devices and under the same ambient conditions. A constant noise level gave a constant reference signal so the dynamics of changes parameter expressed by Eq. (4) referred to the same value of $\mu_{\mathrm{R}}$. Due to that, the analysis of the sound signal was performed without the noise discrimination from the original signal. The possible method for the separation of the sound signal related to the cutting process and to the noise generated by the drives and elements of a machine tool was developed and applied by Licow et al. [19] in the study related to the wood cutting process characterized by the higher sound level.

\subsection{Vibration signals}

The $\mathrm{X}_{3}$ direction is parallel, and $\mathrm{Y}_{3}$ and $\mathrm{Z}_{3}$ directions are perpendicular to the axis of the spindle rotation. The highest values of DCDP of vibration signals were achieved in $Z_{1}$ and $\mathrm{Z}_{3}$ directions of signal measurements conducted by both transducers - Table 2 . The $Z_{1}$ direction of a single-axis transducer is the same as the $Z_{3}$ direction of a triaxial transducer. In addition, these directions correspond to the $\mathrm{Y}^{\prime}$ axis, along which the resultant cutting force has the highest value during turning operations, comparing to the forces acting along $X^{\prime}$ and $Z$ ' axes. This is the effect of the main $F_{c}$ and radial $F_{r}$ cutting forces acting along $\mathrm{Y}$ and $\mathrm{X}$ axes of the workpiece coordinate system, respectively-Fig. 6. It explains also the effectiveness of TCMSs based on cutting force signals as presented in [24, 29, 37, 40]. Considering above, the further analysis was performed in the direction $Z_{3}$ perpendicular to the axis spindle, and parallel to the $Y^{\prime}$ axis. Figure 7 presents
Fig. 3 The analysis of VA signals for the process identification during machining on a mill-turn center

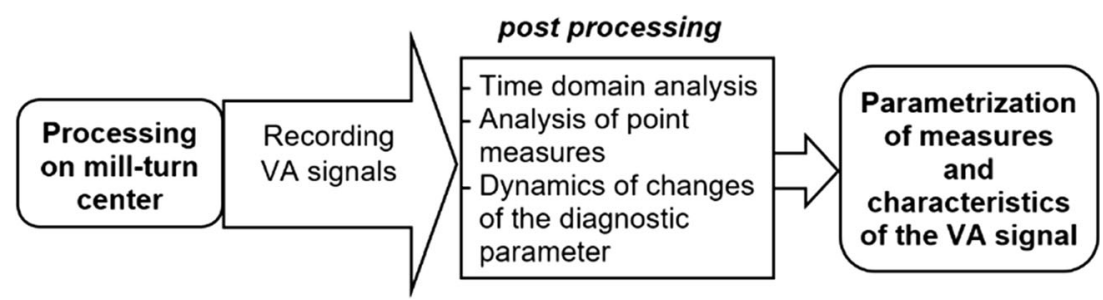


Fig. 4 Time domain analysis of vibroacoustic signals generated during test no. 1 and no. 2

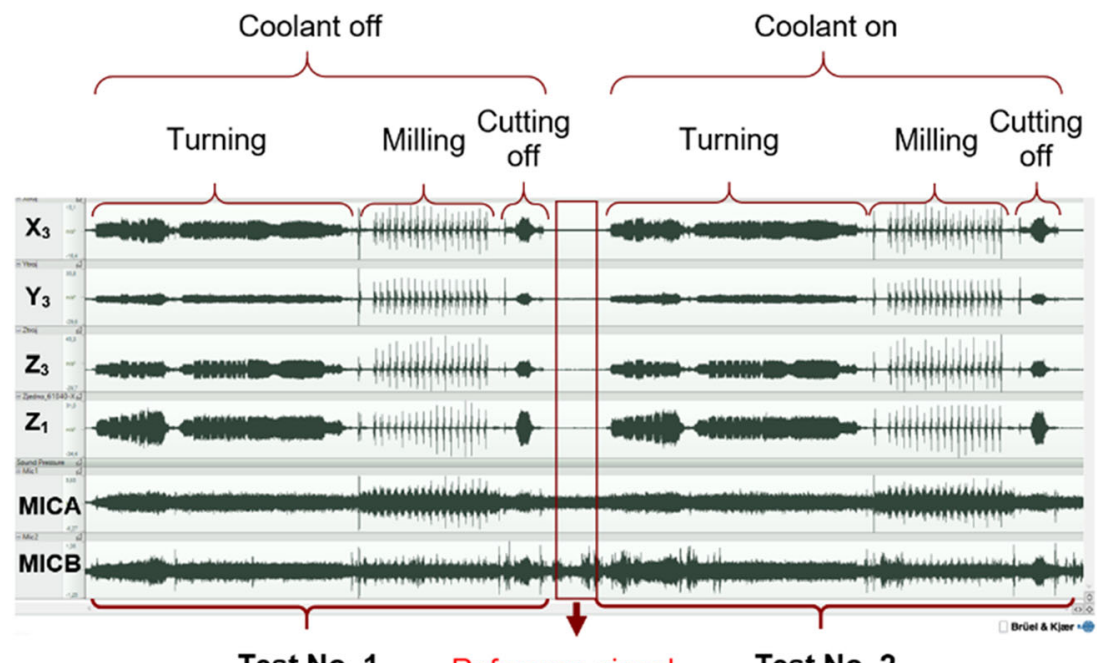

Test No. 1
Reference signal the peak values $S_{\text {PEAK }}$ evaluated for the vibration direction $Z_{3}$ characterized by the high dynamic changes during all tests and processes.

As it can be seen in Fig. 7, the highest $S_{\text {PEAK values (above }}$ $12 \mathrm{~m} / \mathrm{s}^{2}$ ) were recorded during turning in test no. 3 and no. 4 , when the material removal process was carried out. During the test no. 1 , with no material removal, $S_{\text {PEAK }}$ value for turning was approximately three times lower than during machining and at the same level as for cutting off carried out with the same kinematics as turning, with a rotating main spindle. Different kinematics of milling resulted in slightly higher values of $S_{\text {PEAK }}$. What is interesting, the vibrations during cutting off were at a similar level (about $4.5 \mathrm{~m} / \mathrm{s}^{2}$ ) during all tests so it was the most stable process among those analyzed. The highest $S_{\text {PEAK }}$ value for milling was observed during the third test. Increasing the feed speed of the rapid movements to $100 \%$ of the feed declared under G00 command reduced the peak vibration level for turning and milling by approximately $0.5 \mathrm{~m} / \mathrm{s}^{2}$ in the fourth test. Besides, the peak vibration level for milling was the same as during the second test with no material removal.
In the next step of the analysis, the crest factor was calculated for all tests and processes, including the direction of vibrations. As seen in Fig. 8, the highest values of $C_{A}$ were obtained for the time window corresponding to the milling process-Fig. 4. During milling on a lathe, the angular position of the main spindle is set according to a CNC part program and the workpiece is stationary. The milling tool is rotating at the rotational speed set in a part program. Significant differences between the maximum and minimum values of vibrations generated during a milling process (Fig. 4) resulted in higher values of $C_{A}$ (Fig. 8). Switching the coolant on in the second test reduced the vibrations which was also reflected by smaller differences in values of $C_{A}$ estimated for different directions of vibrations during milling and cutting off. Increasing, in the fourth test, the feed speed of the rapid movements to $100 \%$ of the feed declared under G00 command, and the working feed to $110 \%$ of the feed declared under F command had a positive effect on reducing vibration levels in all directions for turning, milling and cutting off_-Fig. 8d. It was probably the effect of indirect damping by reducing clearance
Table $2 S_{\mathrm{RMS}}$ and DCDP point measures estimated for vibration and sound signals registered during the test no. 1

\begin{tabular}{|c|c|c|c|c|c|c|}
\hline Signal & Vibratiol & & & & Sound & \\
\hline Direction & $\mathrm{X}_{3}$ & $\mathrm{Y}_{3}$ & $\mathrm{Z}_{3}$ & $\mathrm{Z}_{1}$ & MIC A & MIC B \\
\hline Point measure & \multicolumn{6}{|c|}{ Root mean square amplitude $S_{\mathrm{RMS}}$} \\
\hline Units & \multicolumn{4}{|c|}{$\left(\mathrm{m} / \mathrm{s}^{2}\right)$} & \multicolumn{2}{|l|}{$(\mathrm{dB})$} \\
\hline Reference signal (idle work) & 0.111 & 0.206 & 0.123 & 0.077 & 86.1 & 74.5 \\
\hline Turning & 1.360 & 1.120 & 3.320 & 2.920 & 87.9 & 74.9 \\
\hline Milling & 0.490 & 0.760 & 1.040 & 0.410 & 92.1 & 74.6 \\
\hline Cutting off & 1.140 & 1.010 & 1.670 & 2.520 & 88.2 & 76.3 \\
\hline Point measure & \multicolumn{6}{|c|}{ Dynamics of changes of the diagnostic parameter DCDP } \\
\hline Units & \multicolumn{6}{|l|}{$(\mathrm{dB})$} \\
\hline Turning & 21.761 & 14.712 & 28.621 & 31.542 & 0.179 & 0.046 \\
\hline Milling & 12.897 & 11.282 & 18.543 & 14.407 & 0.595 & 0.011 \\
\hline Cutting off & 20.231 & 13.809 & 22.656 & 30.264 & 0.209 & 0.207 \\
\hline
\end{tabular}


Fig. 5 A triaxial vibration transducer for measuring signals in three perpendicular directions (a) with reference to the workpiece coordinate systems (b)
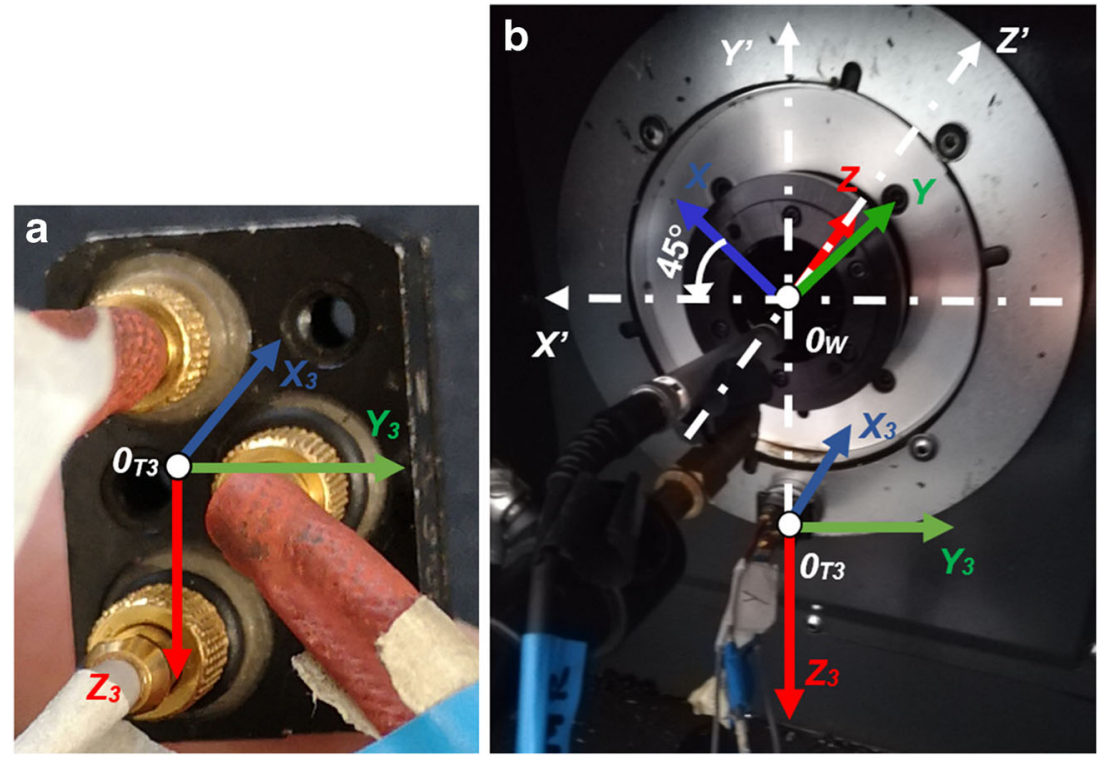

between mechanical components of a machine tool during faster positional movements.

\subsection{Acoustic signals}

Figure 9 shows $S_{\text {PEAK }}$ values of sound signals recorded in two measuring points A and B by microphones: MIC A and MIC $\mathrm{B}$, respectively. The MIC A microphone, located behind the spindle, recorded significantly higher sound level values than the MIC B microphone located $200 \mathrm{~mm}$ from the cover of a machine tool at the height of the spindle axis. For a turning process, the highest $S_{\text {PEAK }}$ values of $98 \mathrm{~dB}$ and $103 \mathrm{~dB}$ were recorded by MIC A during test no. 3 and No. 4, correspondingly. The highest $S_{\text {PEAK }}$ values of vibrations were registered at point $A$ also during turning but by the triaxial transducer in $\mathrm{Z}_{3}$ direction-Fig. 7, test no. 3 and no. 4. Moreover, the sound level is increasing during subsequent tests of turning and decreasing during subsequent tests of cutting off and milling (except for the test no. 4 for milling). The $S_{\text {PEAK }}$ values of sound signals recorded by MIC B are characterized by the smaller dispersion as compared with corresponding results obtained from MIC A.

Similarly as for $S_{\mathrm{PEAK}}$, smaller dispersion of the values of the crest factor $C_{A}$, ranging from 1.15 to 1.25 , was obtained for microphone MIC B-Fig. 10b. The microphone MIC A, placed behind the main spindle, registered signals for which this point measure falls within the range of values from 1.1 to 1.4-Fig. 10a. The $S_{\mathrm{RMS}}$ point measure of the sound signal was also characterized by small differences in the estimated values, as shown in Table 2 for the test no 1. As a result, the values of the DCDP point measure estimated for the sound signals were much lower than for the vibration signals. This indicated that the sound signals registered by microphones were less effective in distinguishing between different processes running in the working space of a machine tool than the vibration signals registered by all transducers.
Fig. 6 The directions of cutting forces during turning with respect to the workpiece coordinate system

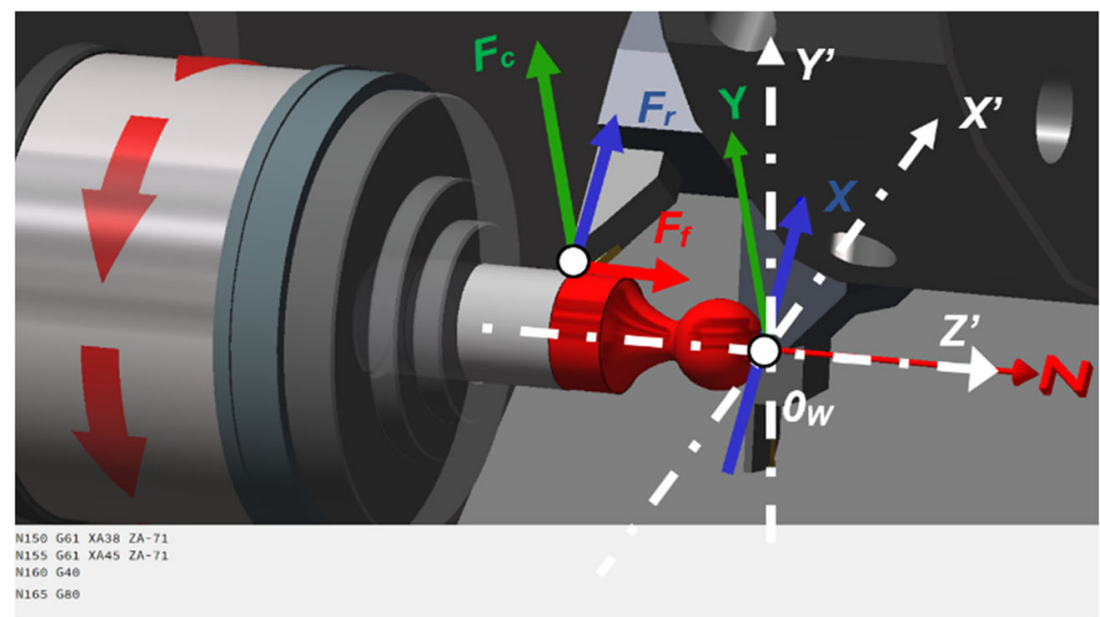


Fig. $7 S_{\text {PEAK }}$ values of acceleration recorded by a threeaxis vibration transducer in $\mathrm{Z}_{3}$ direction, for all tests and processes

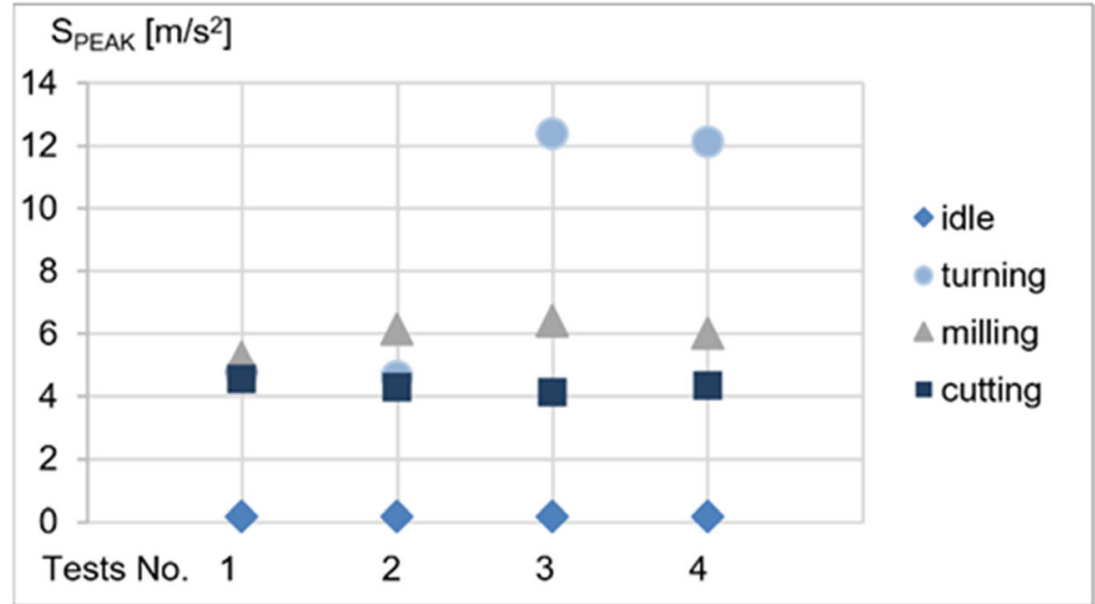

Nevertheless, the MIC A microphone located behind the spindle allowed recording of not only higher sound levels but also resulted in a higher effectiveness in separating the changes related to the material removal processes and cutting conditions.

\subsection{Time-frequency analysis of vibration and sound signals}

Time-frequency analysis of vibration signals was performed for all subsequent tests and transducers. Each vibroacoustic signal was analyzed in the range from 20 to $10,000 \mathrm{~Hz}$ but the significant signal changes occurred at the frequency of up to

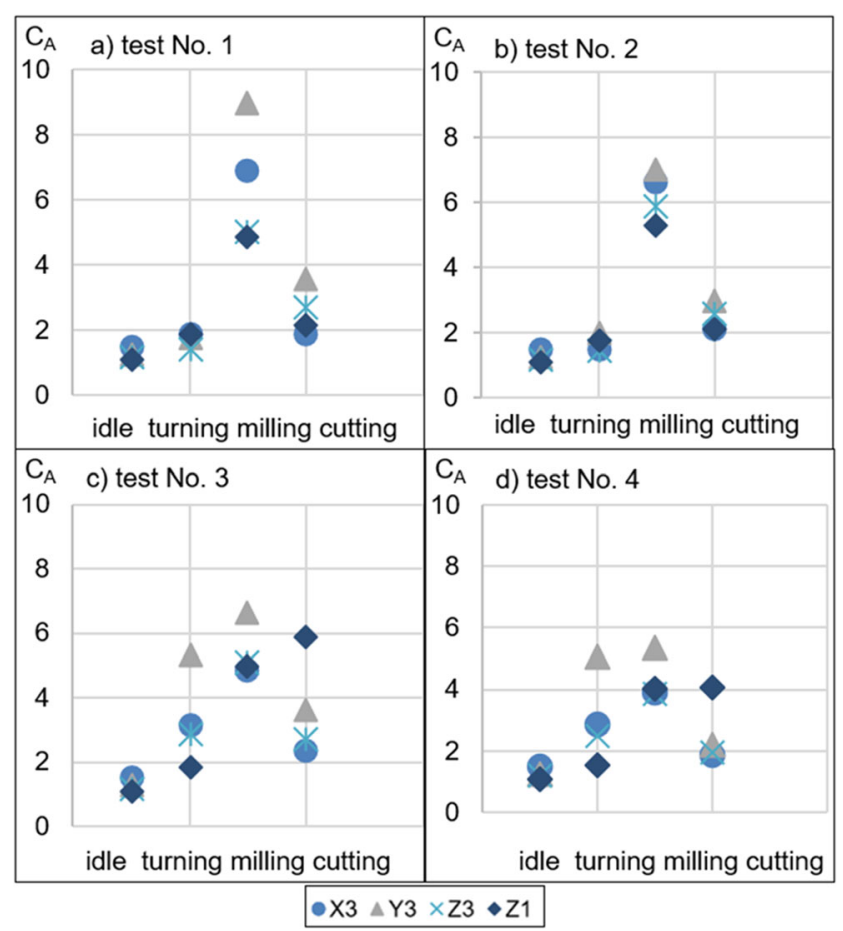

Fig. 8 Crest factor for accelerations during processing and for different vibration directions in subsequent test nos.: (a) 1, (b) 2, (c) 3, (d) 4
$3.200 \mathrm{kHz}$ what is clearly seen in Fig. 11 et seq. The analysis was performed using fast Fourier transform (FFT) without the use of filters. The Hamming time window was selected for the analysis. The time-frequency analysis was performed in the dedicated Reflex Pulse 21 B\&K software.

Figure 11 presents the exemplary vibration signals in the frequency and time domain measured in a $Z_{3}$ direction by a triaxial transducer. For $Z_{1}$ and $Z_{3}$ directions, the diagnostic parameter DCDP had the highest values (Table 2) as these directions correspond to $\mathrm{Y}^{\prime}$ axis along which the force resulting from $F_{c}$ and $F_{r}$ cutting forces is acting (Fig. 5 and Fig. 6). Performed analysis allowed to determine the frequency of the peak values for all subsequent tests. Interestingly, the frequency of the peak values were at the similar level for all relevant processes, regardless of whether the material was removed from the workpiece (test nos. 3 and 4) or not (test nos. 1 and 2). The mean values of the peak frequencies were $1.9 \mathrm{kHz}$ for turning, $200 \mathrm{~Hz}$ for milling and $700 \mathrm{~Hz}$ for cutting off. This is in line with what was indicated by Mou et al. namely, that the spindle rotation in air-cut may have a significant influence on the vibration signal related to the mechanical characteristics of the spindle system [25].

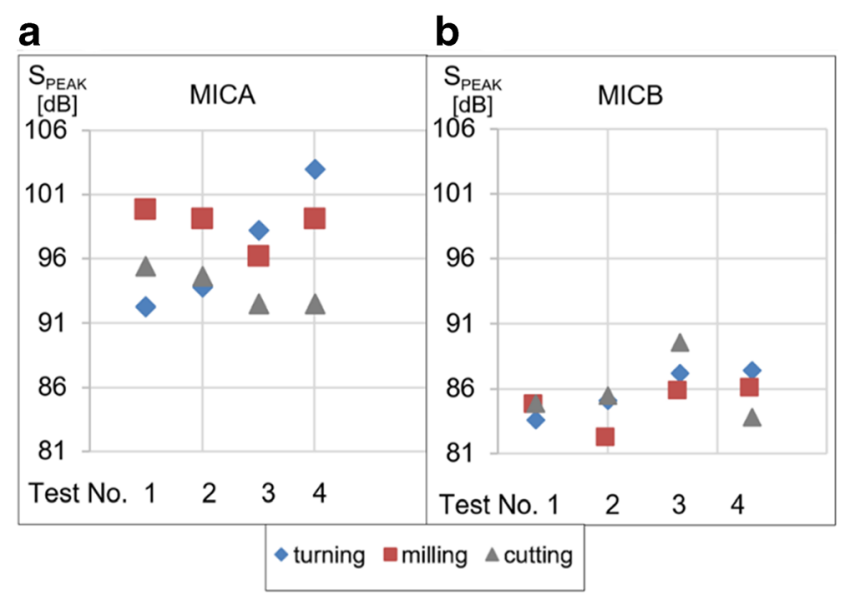

Fig. $9 S_{\text {PEAK }}$ values of sound signals registered by MIC A (a) and MIC B (b) during all tests and processes 


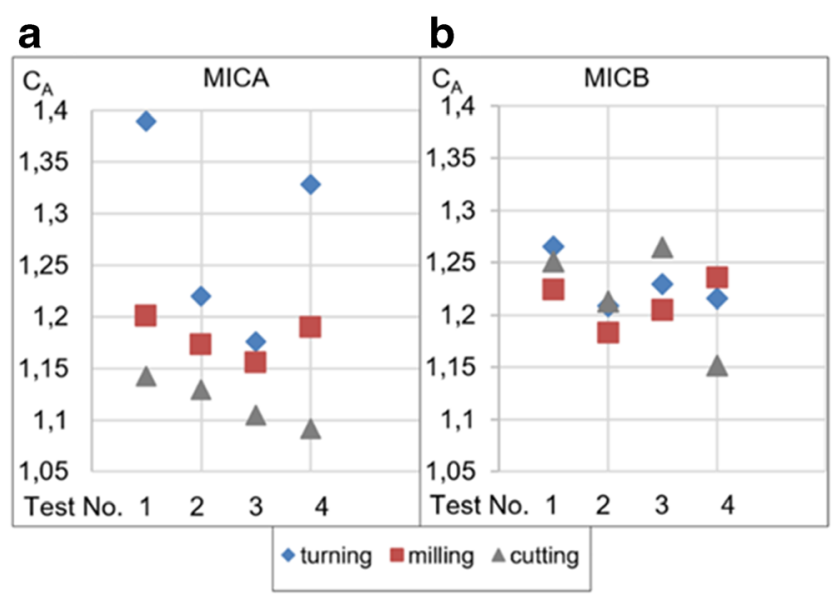

Fig. 10 Crest factor of sound signals registered by MIC A (a) and MIC B (b) for all tests and processes

Figure 12 and Fig. 13 present the vibration signals in the frequency and time domain measured by a triaxial transducer in $\mathrm{X}_{3}$ and $\mathrm{Y}_{3}$ directions, respectively. The peak values, especially in the $X_{3}$ direction (Fig. 12), are lower than for the $Z_{3}$ direction (Fig. 11). Similarly, however, as for a Z3 direction, the characteristic frequencies are comparable for all tests conducted with or without the material removal. The lowest peak values of vibrations were registered by a single axial transducer in a $Z_{1}$ direction (Fig. 14), although the DCDP values presented in Table 1 showed high dynamics of changes for this direction. This confirmed that proposed point measures are good indicators for monitoring the running processes even when the signal amplitude is low. Moreover, frequencies of peak values characteristic for a $Z_{1}$ direction are different than for a $Z_{3}$ direction. It shows that different sensor locations can provide complementary information about the processes.

The acoustic signals measured by MIC A and MIC B are presented in the frequency and time domains in Fig. 15 and Fig. 16, respectively. The amplitude range selected during the analysis was $80 \mathrm{~dB}$, with the maximum value of $110 \mathrm{~dB}$, as the highest $S_{\text {PEAK }}$ value was $103 \mathrm{~dB}$.

The characteristic frequency bandwidths are clearly visible on all charts in Fig. 15 for MIC A, especially in the frequency ranges from 200 to $400 \mathrm{~Hz}$ and 800 to $1000 \mathrm{~Hz}$. Nevertheless, the differences in the amplitudes between all tests are relatively very small, even when the analyzed data are limited to these characteristic bandwidths. The signal registered by the MIC B is the least informative for characterizing the processing changes as there are no characteristic frequencies for the active bandwidths and the amplitudes for different tests are at the similar level-Fig. 16. Similar conclusions were drawn from
Fig. 11 Vibration signals in the frequency and time domain measured in a $Z_{3}$ direction by a triaxial transducer during subsequent test nos.: (a) 1, (b) 2, (c) 3 , (d) 4

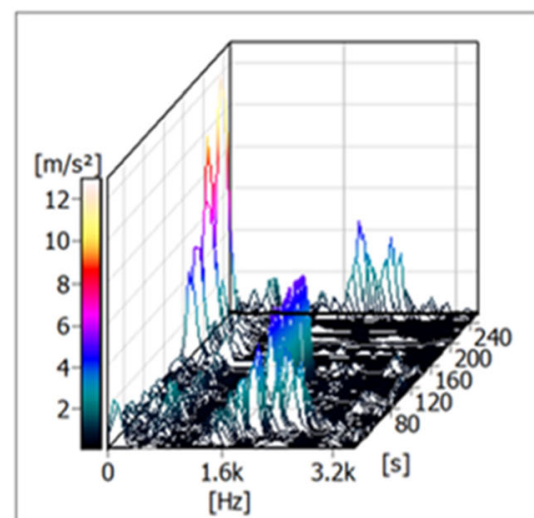

a Test No. 1

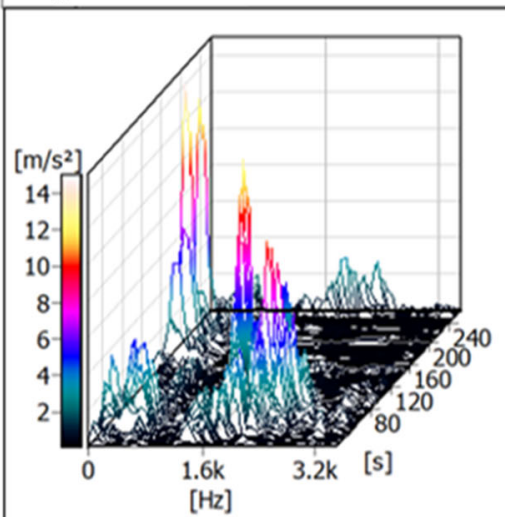

C Test No. 3

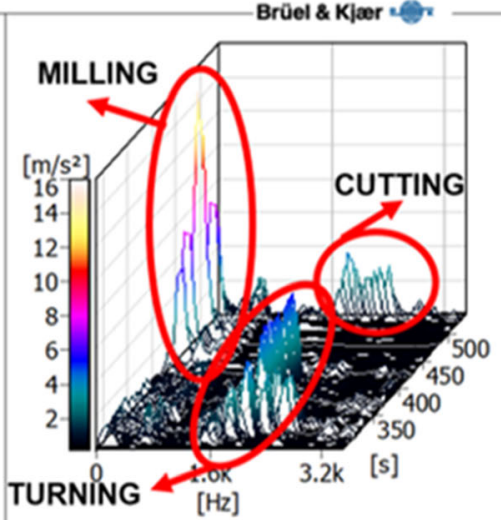

b Test No. 2

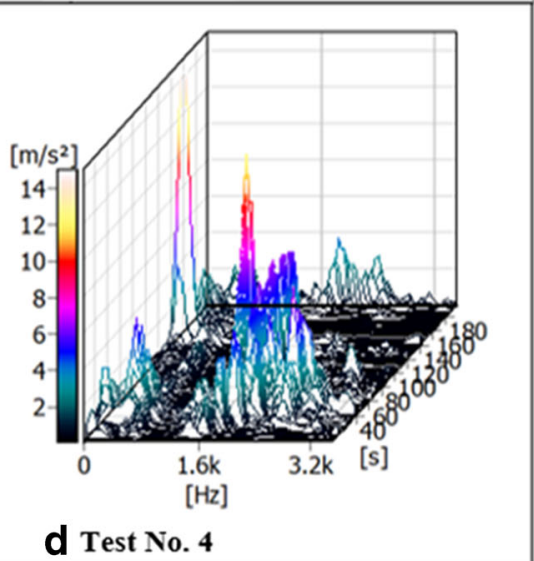


Fig. 12 Vibration signals in the frequency and time domain measured in an $\mathrm{X}_{3}$ direction by a triaxial transducer during subsequent test nos.: (a) 1, (b) 2 , (c) 3 , (d) 4

Fig. 13 Vibration signals in the frequency and time domain measured in a $\mathrm{Y}_{3}$ direction by a triaxial transducer during

subsequent test nos.: (a) 1, (b) 2 , (c) 3 , (d) 4
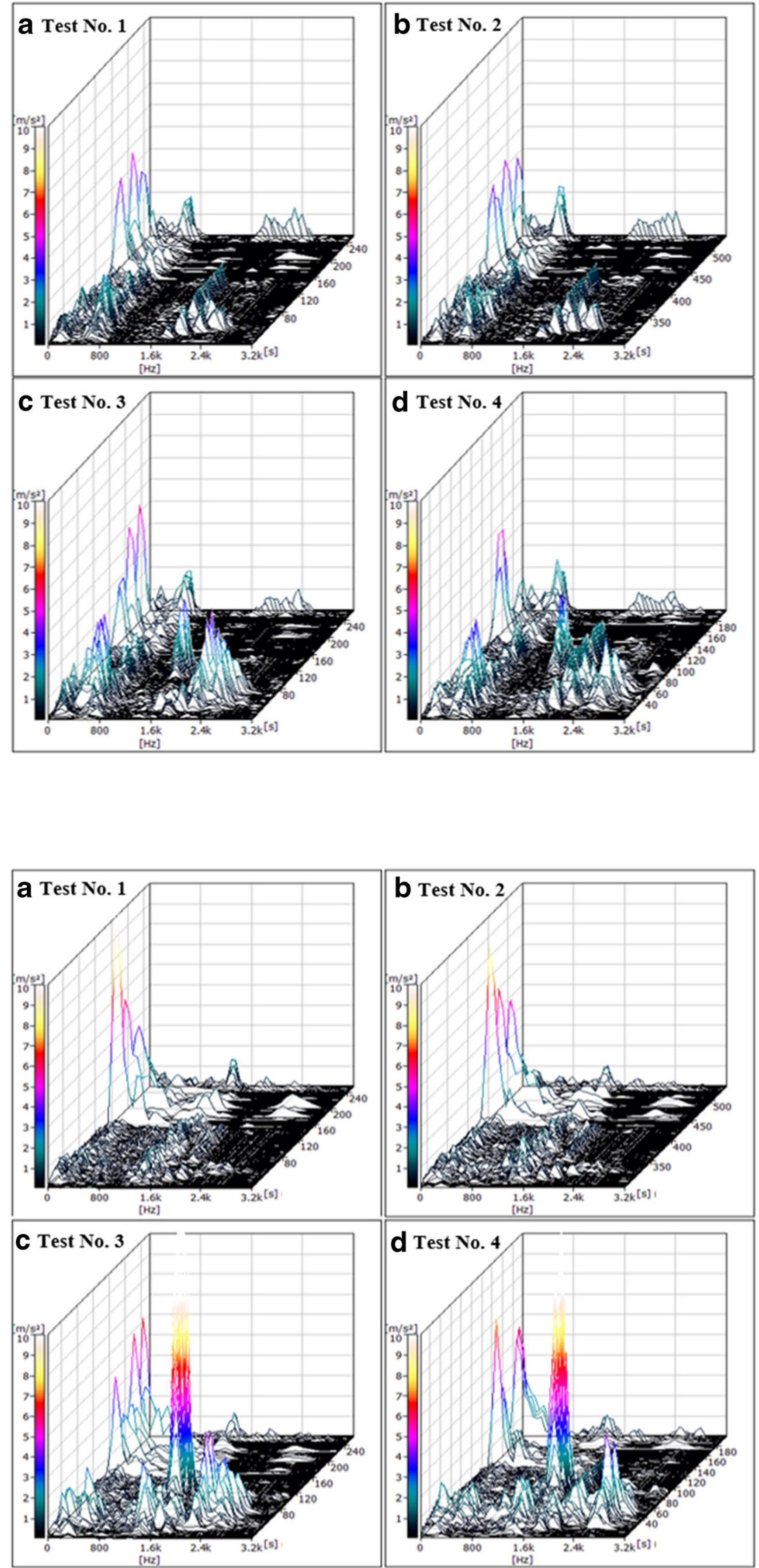
Fig. 14 Vibration signals in the frequency and time domain measured in a $Z_{1}$ direction by a single-axis transducer during subsequent test nos.: (a) 1, (b) 2, (c) 3, (d) 4

Fig. 15 Sound signals in the frequency and time domain measured by a MIC A microphone during subsequent test nos.: (a) 1, (b) 2, (c) 3, (d) 4
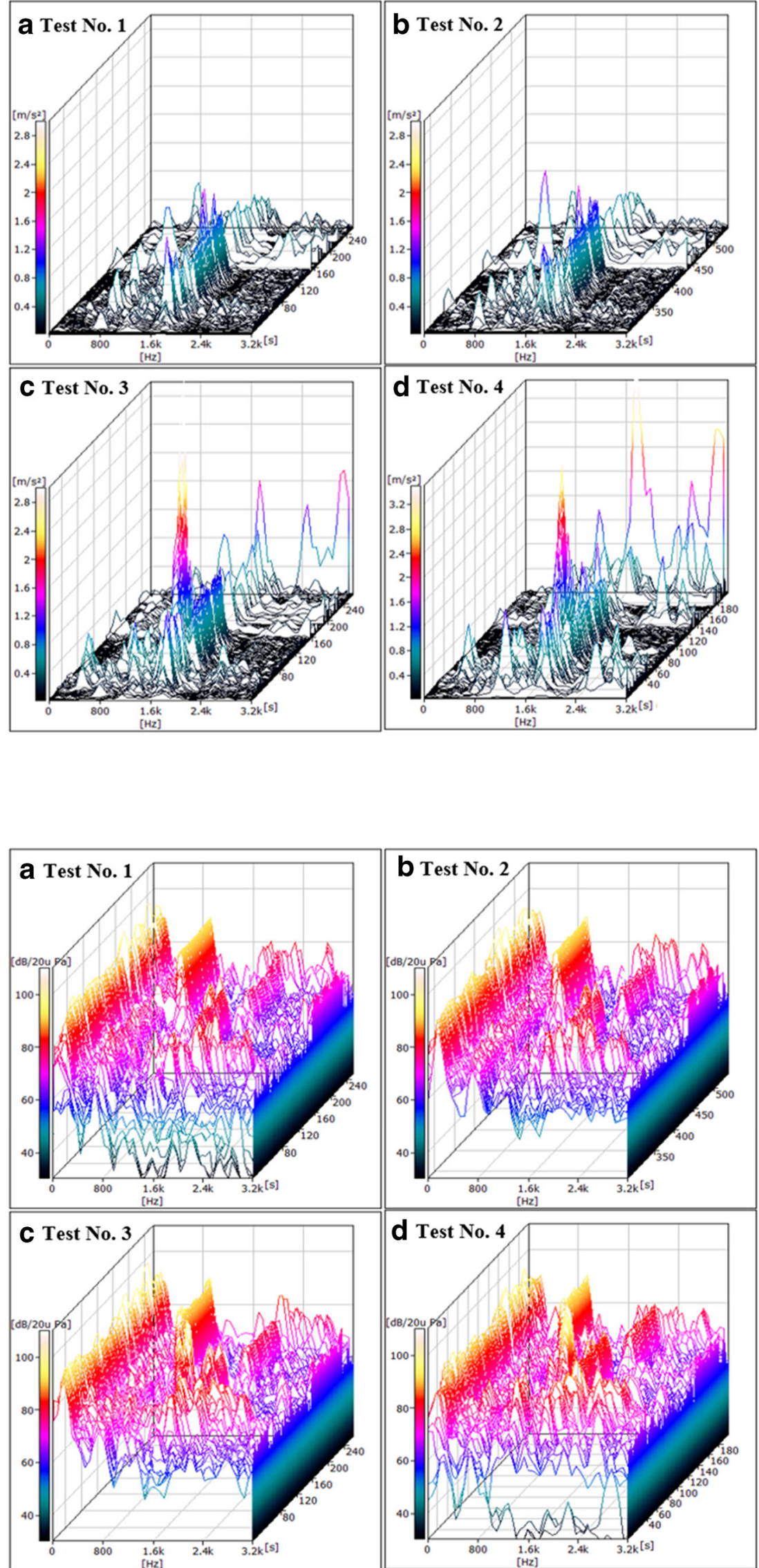
Fig. 16 Sound signals in the frequency and time domain measured by a MIC B microphone during subsequent test nos.: (a) 1, (b) 2, (c) 3, (d) 4

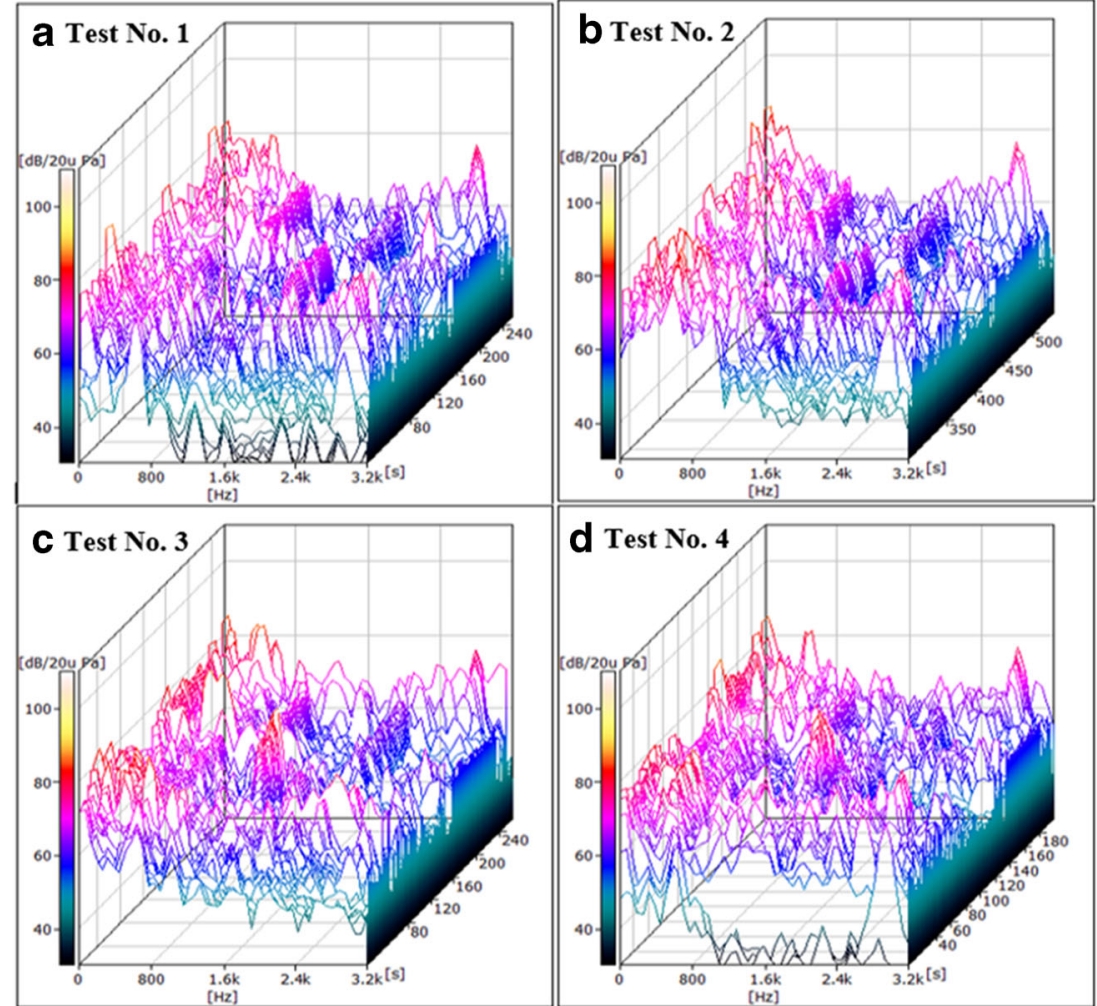

the analysis related to the point measures (Section 5.2) where the sound signal recorded by MIC B was characterized by the smaller dispersion of estimated parameter values comparing to corresponding signal from MIC A. Obtained results confirmed the observations of Zhong et al. [32] who suggested the separation method for recovering the feature sound signals from observed signals as the feature sound may be hidden.

\section{Summary}

The monitoring of cutting processes, realized in complex machine tools equipped with multiple spindles and turrets allowing simultaneous performance of various operations, is one of the biggest challenges and expectations from the modern industry which is increasingly using this type of machines. This paper presents one of the first attempts for the assessment of different processes, i.e., turning and milling, which are performed to produce a mill-turn part on a MTM. The conducted research showed that cutting processes can be characterized with using selected point measures of vibroacoustic signals. The obtained results indicated the most suitable measuring locations and directions with the highest dynamics of signal changes. The main conclusions from the experiments and analysis are as follows:

- $\quad$ Proposed point measures allowed for the assessment and comparison of different signals, in this case vibration and sound signals;
- The estimated values of DCDP parameters confirmed high effectiveness of the vibration signal collected at the measuring points located outside the cutting and chip evacuation zones allowing process monitoring under the wet and dry conditions;

- Not only different types of sensors but also different locations of the same sensors can provide complementary information about the monitored processes;

- The "air-cut" can determine the characteristic frequencies and bandwidths for the required manufacturing processes;

- The estimated values of DCDP parameters indicated the lower effectiveness of the sound signal in distinguishing between different processes running in the working space of a machine tool. Although the results from the analysis of the sound signal were not fully satisfactory, the location of a MIC A microphone behind the spindle allowed recording higher sound levels and also slightly higher effectiveness in separating changes occurring in the workspace.

- To increase the sound signal efficiency, the microphone should be located much closer to the machining zone. This can be implemented relatively simply for a microphone as the sound sensors are much cheaper than the vibration sensors and their installation is also easier.

Proposed method is relatively simple and suitable for collecting reliable data from the physical environment consisting 
of advanced technological machine tools. The obtained data can be used to build a reference model for the "shaped digital twin" in manufacturing parts with a combination of milling and turning features. Determining the frequency characteristics of manufacturing processes in the "air-cut" and during first test cuttings (before the production) could enable the creation of the reference databases of specific operations necessary to produce the definite spectrum of mechanical components. The data exceeding the range of determined peak values and bandwidths of reference frequencies might indicate an incorrect course of the machining process e.g. due to the excessive tool wear. Presented methodology can be also used as a supporting tool for CAD/ CAM/CAPP software for a better selection of cutting parameters and for a wireless control of manufacturing systems consisting of several machine tools. This will require further research with establishing a more accurate correlation between vibration and acoustic signal to identify the course of machining processes.

Acknowledgments The authors would like to thank the Faculty of Civil and Transport Engineering from the Poznan University of Technology and Bruel and Kjaer Company for the technical support, Dr. Tadeusz Bocheński for performing CNC simulations, and Mr. Sławomir Klimkiewicz for conducting the experiments.

Open Access This article is licensed under a Creative Commons Attribution 4.0 International License, which permits use, sharing, adaptation, distribution and reproduction in any medium or format, as long as you give appropriate credit to the original author(s) and the source, provide a link to the Creative Commons licence, and indicate if changes were made. The images or other third party material in this article are included in the article's Creative Commons licence, unless indicated otherwise in a credit line to the material. If material is not included in the article's Creative Commons licence and your intended use is not permitted by statutory regulation or exceeds the permitted use, you will need to obtain permission directly from the copyright holder. To view a copy of this licence, visit http://creativecommons.org/licenses/by/4.0/.

\section{References}

1. Rao BC (2010) Methodology for adapting metal cutting to a green economy. Proc Inst Mech Eng B J Eng Manuf 224(8):1193-1205

2. Chung DH, Suh SH (2008) ISO 14649-based nonlinear process planning implementation for complex machining. Comput Aided Des 40(5):521-536

3. Naderi B, Azab A (2015) Modeling and scheduling a flexible manufacturing cell with parallel processing capability. CIRP J Manuf Sci Technol 11:18-27

4. Zhang X, Liu R, Nassehi A, Newman ST (2011) A STEPcompliant process planning system for $\mathrm{CNC}$ turning operations. Robot Comput Integr Manuf 27(2):349-356

5. Djassemi M (2009) Emergence of multitasking machining systems: applications and best selection practices. J Manuf Technol Manag 20 (1):130-142

6. Deja M, Siemiatkowski MS (2018) Machining process sequencing and machine assignment in generative feature-based CAPP for mill-turn parts. J Manuf Syst 48:49-62
7. Mourtzis D, Vlachou E, Xanthopoulos N, Givehchi M, Wang L (2016) Cloud-based adaptive process planning considering availability and capabilities of machine tools. J Manuf Syst 39:1-8

8. Yusof Y, Latif K (2014) Survey on computer-aided process planning. Int J Adv Manuf Technol 75(1-4):77-89

9. Xu X, Wang L, Newman ST (2011) Computer-aided process planning-a critical review of recent developments and future trends. Int J Comput Integr Manuf 24(1):1-31

10. Deja M, Siemiatkowski M (2014) Generative process planning with reasoning based on geometrical product specification. In: Key Engineering Materials, vol 597, pp 159-164 Trans Tech Publications Ltd

11. Deja M, Siemiatkowski M, Sender P (2017) Comparative study of machining technology selection to manufacture large-size components of offshore constructions. Polish Marit Res 24(s1):38-45

12. Lu Y, Liu C, Kevin I, Wang K, Huang H, Xu X (2020) Digital twindriven smart manufacturing: connotation, reference model, applications and research issues. Robot Comput Integr Manuf 61:101837

13. Schleich B, Anwer N, Mathieu L, Wartzack S (2017) Shaping the digital twin for design and production engineering. CIRP Ann 66(1):141-144

14. Rubio EM, Teti R (2009) Cutting parameters analysis for the development of a milling process monitoring system based on audible energy sound. J Intell Manuf 20(1):43-54

15. Teti R, Jemielniak K, O’Donnell G, Dornfeld D (2010) Advanced monitoring of machining operations. CIRP Ann 59(2):717-739

16. Roth JT, Djurdjanovic D, Yang X, Mears L, Kurfess T (2010) Quality and inspection of machining operations: tool condition monitoring. J Manuf Sci Eng 132(4):041015

17. Lauro CH, Brandão LC, Baldo D, Reis RA, Davim JP (2014) Monitoring and processing signal applied in machining processes - a review. Measurement 58:73-86

18. Kishawy HA, Hegab H, Umer U, Mohany A (2018) Application of acoustic emissions in machining processes: analysis and critical review. Int J Adv Manuf Technol 98(5-8):1391-1407

19. Licow R, Chuchala D, Deja M, Orlowski KA, Taube P (2020) Effect of pine impregnation and feed speed on sound level and cutting power in wood sawing. J Clean Prod 272(1):122833

20. Zhang JZ, Chen JC (2008) Tool condition monitoring in an endmilling operation based on the vibration signal collected through a microcontroller-based data acquisition system. Int J Adv Manuf Technol 39(1-2):118-128

21. Wu TY, Lei KW (2019) Prediction of surface roughness in milling process using vibration signal analysis and artificial neural network. Int J Adv Manuf Technol 102(1-4):305-314

22. Kalinski KJ, Galewski MA (2015) Optimal spindle speed determination for vibration reduction during ball-end milling of flexible details. Int J Mach Tools Manuf 92:19-30

23. Kaliński KJ, Galewski MA, Mazur M, Chodnicki M (2017) Modelling and simulation of a new variable stiffness holder for milling of flexible details. Polish Marit Res 24(s1):115-124

24. Sun W, Luo M, Zhang D (2020) Machining vibration monitoring based on dynamic clamping force measuring in thin-walled components milling. Int J Adv Manuf Technol 107:2211-2226

25. Mou W, Jiang Z, Zhu S (2019) A study of tool tipping monitoring for titanium milling based on cutting vibration. Int J Adv Manuf Technol 104(9-12):3457-3471

26. Xie Z, Li J, Lu Y (2018) An integrated wireless vibration sensing tool holder for milling tool condition monitoring. Int J Adv Manuf Technol 95(5-8):2885-2896

27. Liu H, Tang S, He S, Li B, Mao X, Peng F (2016) A method of measuring tool tip vibration in turning operations. Int J Adv Manuf Technol 85(5-8):1325-1337

28. Hsieh WH, Lu MC, Chiou SJ (2012) Application of backpropagation neural network for spindle vibration-based tool 
wear monitoring in micro-milling. Int J Adv Manuf Technol 61(14):53-61

29. Jáuregui JC, Reséndiz JR, Thenozhi S, Szalay T, Jacsó Á, Takács $M(2018)$ Frequency and time-frequency analysis of cutting force and vibration signals for tool condition monitoring. IEEE Access 6 : 6400-6410

30. Lu MC, Wan BS (2013) Study of high-frequency sound signals for tool wear monitoring in micromilling. Int J Adv Manuf Technol 66(9-12):1785-1792

31. Siddhpura A, Paurobally R (2013) A review of flank wear prediction methods for tool condition monitoring in a turning process. Int J Adv Manuf Technol 65(1-4):371-393

32. Zhong ZM, Chen J, Zhong P, Wu JB (2006) Application of the blind source separation method to feature extraction of machine sound signals. Int J Adv Manuf Technol 28(9-10):855-862

33. Salgado DR, Alonso FJ (2007) An approach based on current and sound signals for in-process tool wear monitoring. Int J Mach Tools Manuf 47(14):2140-2152

34. Ai CS, Sun YJ, He GW, Ze XB, Li W, Mao K (2012) The milling tool wear monitoring using the acoustic spectrum. Int J Adv Manuf Technol 61(5-8):457-463

35. Kothuru A, Nooka SP, Liu R (2018) Application of audible sound signals for tool wear monitoring using machine learning techniques in end milling. Int J Adv Manuf Technol 95(9-12):3797-3808

36. Kothuru A, Nooka SP, Liu R (2018) Audio-based tool condition monitoring in milling of the workpiece material with the hardness variation using support vector machines and convolutional neural networks. J Manuf Sci Eng 140(11):111006

37. Shankar S, Mohanraj T, Rajasekar R (2019) Prediction of cutting tool wear during milling process using artificial intelligence techniques. Int J Comput Integr Manuf 32(2):174-182

38. Madhusudana CK, Kumar H, Narendranath S (2017) Face milling tool condition monitoring using sound signal. Int J Syst Assur Eng Manag 8(2):1643-1653

39. Madhusudana CK, Kumar H, Narendranath S (2018) Fault diagnosis of face milling tool using decision tree and sound signal. Mater Today Proc 5(5):12035-12044
40. Bağci E (2017) Experimental investigation of effect of tool path strategies and cutting parameters using acoustic signal in complex surface machining. J Vibroeng 19(7):5571-5588

41. Cao H, Yue Y, Chen X, Zhang X (2017) Chatter detection in milling process based on synchrosqueezing transform of sound signals. Int J Adv Manuf Technol 89(9-12):2747-2755

42. Lu MC, Kannatey-Asibu E Jr (2004) Flank wear and process characteristic effect on system dynamics in turning. J Manuf Sci Eng 126(1):131-140

43. Seemuang N, McLeay T, Slatter T (2016) Using spindle noise to monitor tool wear in a turning process. Int J Adv Manuf Technol 86(9-12):2781-2790

44. Carou D, Rubio EM, Lauro CH, Brandão LC, Davim JP (2017) Study based on sound monitoring as a means for superficial quality control in intermittent turning of magnesium workpieces. Procedia CIRP 62:262-268

45. Yusof MFM, Kamaruzaman MA, Ishak M, Ghazali MF (2017) Porosity detection by analyzing arc sound signal acquired during the welding process of gas pipeline steel. Int J Adv Manuf Technol 89(9-12):3661-3670

46. Ubhayaratne I, Pereira MP, Xiang Y, Rolfe BF (2017) Audio signal analysis for tool wear monitoring in sheet metal stamping. Mech Syst Signal Process 85:809-826

47. Deja M (2014) Vertical vibration reduction and audible sound analysis in surface grinding with electroplated tools. J Meas Eng 2(2):80-85

48. Hosokawa A, Mashimo K, Yamada K, Ueda T (2004) Evaluation of grinding wheel surface by means of grinding sound discrimination. JSME Int J Ser C Mech Syst Mach Elem Manuf 47(1):52-58

49. Licow R. (2018) The assessment of the defects on rail running surface by the use of vibroacoustic phenomena. PhD Thesis, Politechnika Poznańska, 2018 (in Polish)

Publisher's note Springer Nature remains neutral with regard to jurisdictional claims in published maps and institutional affiliations. 